\title{
THE KECK CARBON CYCLE AMS LABORATORY, UNIVERSITY OF CALIFORNIA, IRVINE: INITIAL OPERATION AND A BACKGROUND SURPRISE
}

\author{
John Southon ${ }^{1} \bullet$ Guaciara Santos $^{1} \bullet$ Kevin Druffel-Rodriguez $^{1,2} \bullet$ Ellen Druffel $^{1} \bullet$ Sue Trumbore ${ }^{1}$ \\ Xiaomei $\mathrm{Xu}^{1} \bullet$ Sheila Griffin ${ }^{1} \bullet$ Shahla Ali ${ }^{1,3} \cdot$ Maya Mazon ${ }^{1,4}$ \\ ABSTRACT. A new radiocarbon accelerator mass spectrometry (AMS) laboratory for carbon cycle studies has been \\ established at the University of California, Irvine. The 0.5MV AMS system was installed in mid-2002 and has operated \\ routinely since October of that year. This paper briefly describes the spectrometer and summarizes lessons learned during the \\ first year of operation. In the process of setting up the system, we identified and largely suppressed a previously unreported \\ ${ }^{14} \mathrm{C}$ AMS background: charge exchange tails from ${ }^{14} \mathrm{~N}$ beams derived from nitrogen-containing molecular ions produced near \\ the entrance of the accelerator.
}

\section{THE KCCAMS FACILITY}

The Keck Carbon Cycle accelerator mass spectrometry (KCCAMS) facility was established in 2001-2002 with a \$2M grant from the W M Keck Foundation and matching funds from University of California, Irvine (UC Irvine), and was set up to use carbon isotopic techniques, primarily AMS, to advance understanding of the carbon cycle and its linkages with climate. The facility consists of 3 major elements:

1. A National Electrostatics (NEC) 0.5MV 1.5SDH-1 accelerator mass spectrometry (AMS) system with a 40-sample MC-SNICS ion source;

2. A Finnegan MAT Delta Plus Isotope Ratio Mass Spectrometer equipped with Gas Bench and Elemental Analyzer (Fisons 1500NC) inputs for gas and solid organic samples, respectively;

3. A new sample preparation laboratory with two 12-head graphitizer lines to supplement existing UC Irvine sample preparation facilities.

\section{AMS HARDWARE}

The spectrometer (Figure 1) is the third NEC production model in a new generation of compact AMS systems developed in collaboration with ETH-Zurich (Synal et al. 2000). Our system has several improvements over previous versions delivered to Georgia (Roberts et al. 2003) and Poznań (Goslar et al. 2003). These include the use of large cryopumps (Cryotorr 8's) to improve vacuum and, thus, reduce backgrounds due to ions scattering from residual gas, and provision of extra beam diagnostics (beam profile monitors and adjustable slits) and additional corrective steerers (Figure 1). A larger than normal $\mathrm{SF}_{6}$ gas handling system (NEC \#952 SMB) was specified to allow the accelerator insulating gas to be transferred with minimal losses.

\section{TIMETABLE}

Funding for the facility was received in January 2001 and the AMS system was ordered in April 2001 and installed over a 3-week period in June/July 2002. After some initial delays due to ion source instability problems, the first research unknowns were measured in August 2002 and the system was accepted in October of that year; it has since run routinely. On completion of a new Earth

\footnotetext{
${ }^{1}$ Earth System Science Department, University of California, Irvine, California 92612, USA.

${ }^{2}$ Department of Chemistry, Loyola Marymount University, Seaver Hall, Los Angeles, California, USA.

${ }^{3}$ Lamont-Doherty Earth Observatory, Columbia University, Palisades, New York, USA.

${ }^{4}$ Department of Biology, California State University, Fullerton, California, USA.
} 


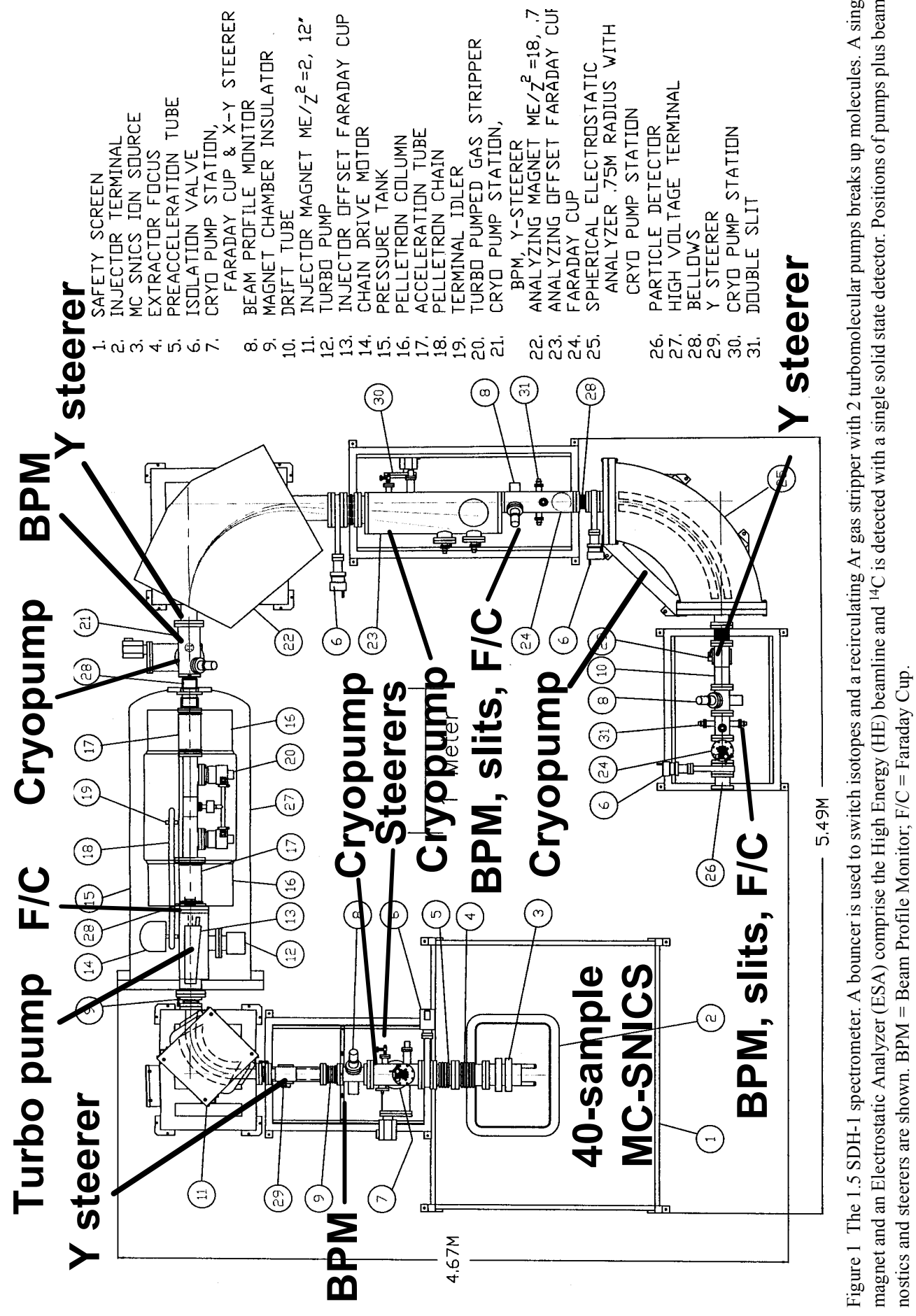


System Science building in July 2003, the entire facility was moved over a 4-week period, including time spent dismantling and rebuilding the sample prep lab. Four to 6 people worked on the project at any given time, including an NEC engineer who supervised reinstallation of the spectrometer. The last AMS run before the move was on June 29 and tests on July 17 showed that the spectrometer was working satisfactorily in its new home, just 19 days later. We certainly do not recommend moving an AMS system every year, but this timetable does illustrate an advantage of these small machines.

\section{THE FIRST YEAR OF OPERATION}

Our overall impression after a year of operation is that the system works well. The hardware is reliable and well interlocked, and unattended running overnight is routine. In particular, the ion source sample changer (arguably the most complex part of any AMS system) has been almost trouble-free. The small sample holders for the MC-SNICS source-too small to be labeled-are worrisome, and we are working on an alternative design (Southon and Santos, these proceedings). NEC's AccelNET control software has proven very reliable, though ease of use would be significantly improved if more features were incorporated into the present Graphical User Interface. Notable pluses of the control system are excellent implementations of a strip chart module for system monitoring and software-assignable knobs and meters for tuning. We use NEC's standard data acquisition software, but rely on the Lawrence Livermore (LLNL) Fudger code (T Ognibene, personal communication) for data analysis. However, we routinely use the strip chart feature of the NEC analysis code (abc) to scan the cycle by cycle data records to investigate anomalous results. This feature also alerted us to 2 problems which affected the ${ }^{13} \mathrm{C} / 12 \mathrm{C}$ measurements: data overwriting due to an incorrectly set jumper in a CAMAC memory module, and synchronization errors due to a wrongly selected polarity on a current integrator timing output.

Of course, significant problems have occurred. Accelerator sparks damaged cooling fans inside the tank, until we added extra shielding around the AC power inputs. Initially, the ion source showed gross instability, eventually traced to an electrical short that provided a bypass for the current heating the Cs supply line. A turbomolecular pump in the accelerator gas stripper (Leybold TMP151) developed a pressure-sensitive leak due to an aluminum KF-10 blankoff flange that had begun to split under $5 \mathrm{~atm}$ of $\mathrm{SF}_{6}$ and the pump also twice suffered rotor bearing failures. Beam marks on the interior of the accelerator vacuum system indicated that the beam was oval not round and it was eventually determined that the injection magnet had been built with incorrect pole face angles due to a miscommunication between NEC and manufacturer Danfysik. We had hoped that installation of new poles would provide an increased margin for beam transmission through the stripper. However, we observed little change, though beam spots showed that the problem had indeed been corrected.

\section{PERFORMANCE}

Following a number of ion source improvements (Southon and Santos, these proceedings), the source routinely produces $120-170 \mu \mathrm{A}$ of $\mathrm{C}^{-}$from both $\mathrm{Zn}$-reduced and hydrogen-reduced graphite. These outputs allow us to measure a typical wheel of 40 samples to 3-4\%o precision in well under $24 \mathrm{hr}$. Measurement precision and accuracy, based on scatter in results for multiple aliquots of a primary standard plus deviation of secondary standards from the known values are $2-5 \%$, with some runs clearly better than others. The origin of these variations is still unknown. The $\delta^{13} \mathrm{C}$ values measured on-line often drift by several per mil during a run, but most of these drifts normalize out and the normalized values are accurate to $\sim 1-2 \%$. Clearly, there is still room for improvement, but we are encouraged to have reached this level of performance after just $1 \mathrm{yr}$. 


\section{BACKGROUNDS}

\section{I. ${ }^{14} \mathrm{~N}$}

Recent results from graphitized background samples are equivalent to ${ }^{14} \mathrm{C}$ ages as high as $55 \mathrm{ka}$. Initially, however, backgrounds rarely reached $50 \mathrm{ka}$ and exhibited several puzzling features. Count rates were high even with the Low Energy (injection) magnet far off-mass (Figure 2), though they did disappear when the ion source Faraday Cup was inserted. Results from Alfa Aesar synthetic graphite, commonly used as a convenient "machine" blank, were often no better than those from graphitized coal. There was no strong dependence of the background on stripper gas pressure, indicating that it was not due to incomplete destruction of molecules; and the blanks were unchanged when nitrogen was used as the stripper gas instead of argon. Experiments where selected pumps were turned off showed some dependence of blank levels on the vacuum in the HE accelerator tube, or possibly the HE analyzing magnet. Lack of sufficient pumps in suitable locations prevented us from carrying out similar experiments in the injection system.

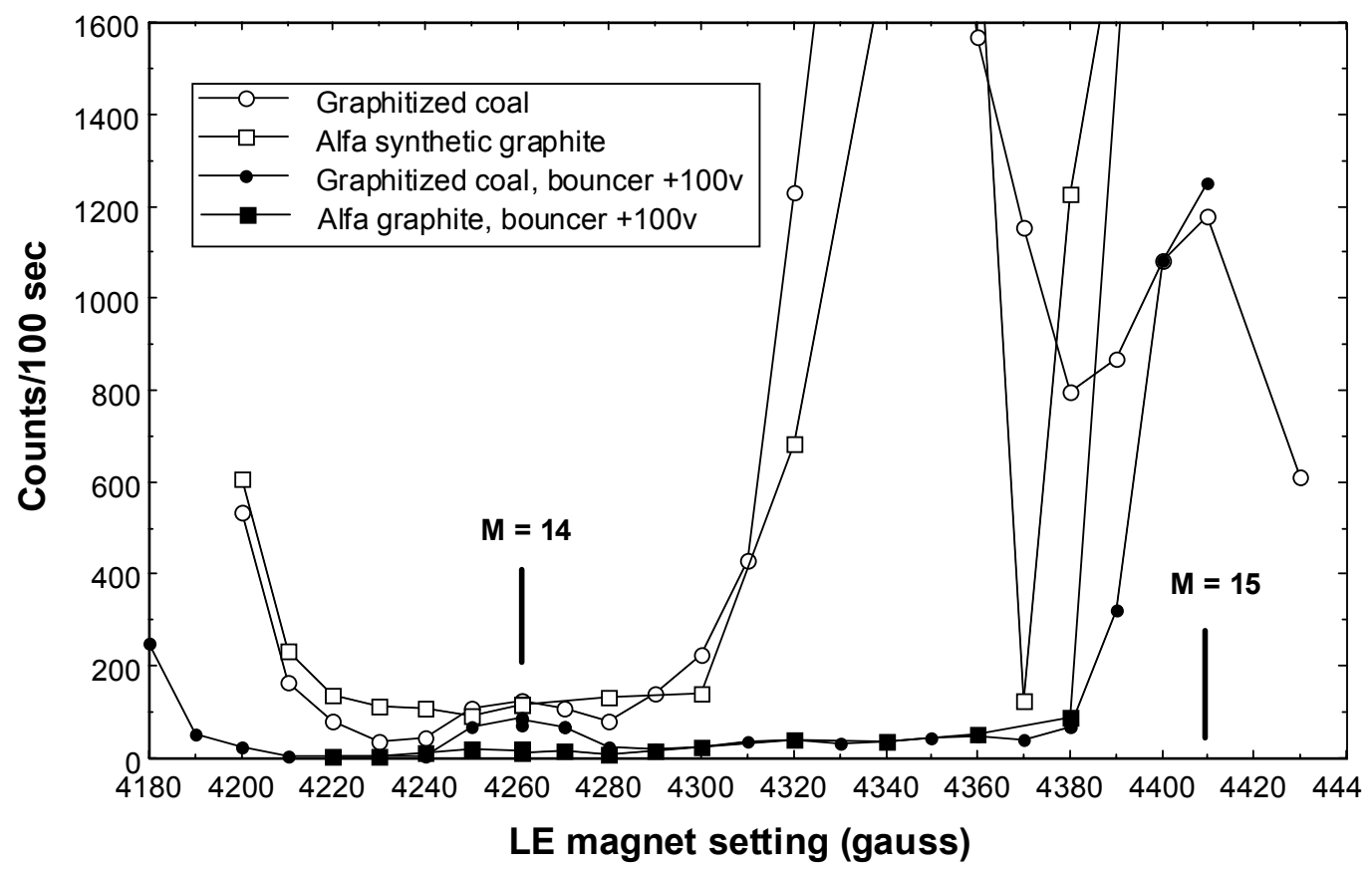

Figure 2 Detector count rate within the ${ }^{14} \mathrm{C}$ energy window versus LE magnet setting, with bouncer voltages of zero and +100 v. Count rates are far lower with a positive voltage on the bouncer.

Efforts to understand the background led us to study in detail the various trace beams emerging from the accelerator under different conditions. Scans of the HE magnet with ${ }^{13} \mathrm{C}$ injected into the accelerator revealed a surprisingly large baseline current or tail of 5-20 pA, or between $10^{-4}$ and $10^{-5}$ of the primary beam (Figure 3). This tail is due to ions which emerge from the stripper in different charge states and charge exchange to $1^{+}$in the HE accelerator tube. The relatively high intensity is ultimately due to the high stripper gas pressures required for destruction of molecules at $0.5 \mathrm{MV}$ (Jacob et al. 2000). Figure 3 also shows a feature near the main ${ }^{13} \mathrm{C}$ peak that is probably due to secondary electrons scattered into the Faraday Cup. Small ( pA) peaks at magnet settings of 7340 and 
7840 gauss are transmitted by the ESA at settings corresponding to E/q equal to the accelerator terminal voltage. This yields $\mathrm{M} / \mathrm{q}=28$ and 32 and we believe these peaks are $\mathrm{N}_{2}{ }^{+}$and $\mathrm{O}_{2}{ }^{+}$from beaminduced ionization of residual air in the stripper. We also see beams of several charge states of Ar from stripper gas ionization, at intensities of $\mathrm{nA}$ to hundreds of $\mathrm{pA}$.

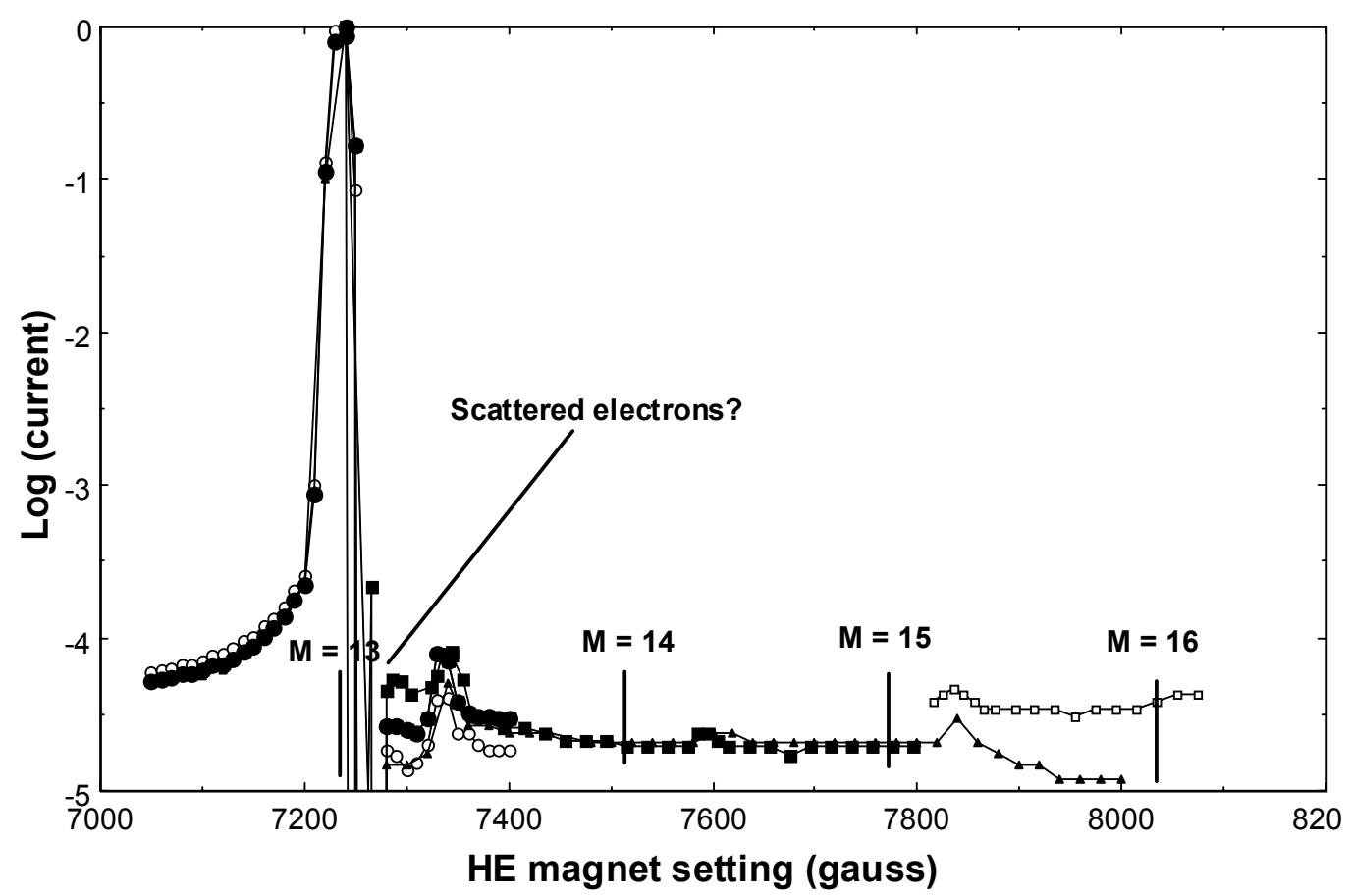

Figure 3 Current in the HE magnet Faraday Cup versus magnet setting, with ${ }^{13} \mathrm{C}$ injected (composite figure from several magnet scans). Current is plotted as a fraction of the current in the primary ${ }^{13} \mathrm{C}$ beam, on a logarithmic scale. A chargeexchange tail extends over the equivalent of several mass units, or an energy range of hundreds of $\mathrm{keV}$.

Scans were also carried out with mass 14 injected and the HE magnet and ESA and the detector energy window varied together at settings appropriate for mass 14 charge state $1+$. Once again, a baseline signal - in this case a " ${ }^{14} \mathrm{C}$ " count rate of around $1 \mathrm{~Hz}$, equivalent to $0.2 \mathrm{pMC}$ (percent modern carbon) or $50 \mathrm{ka}$ - was present at all HE beamline settings, though several peaks were also observed (Figure 4). Experiments where the ESA was varied showed that the ions were transmitted cleanly - i.e. the background was not due to scattering in the ESA. We were forced to accept that the background was truly mass 14 (i.e. nitrogen), made up of charge exchange tails from lower energy peaks, primarily from the intense peak at $815 \mathrm{keV}$ (a $3 \times 10^{-5}$ tail from a $30 \mathrm{KHz}$ peak gives a count rate of $\sim 1 \mathrm{~Hz}$, close to that observed). Recalling that this background was present at all injector settings, we realized that we had purchased a ${ }^{14} \mathrm{C}$ AMS system that consistently produced the interfering isobar, regardless of how it was tuned.

The challenge was then to determine the origin of the ${ }^{14} \mathrm{~N}$. Eventually, we realized that the peaks at 1024,993 , and $815 \mathrm{keV}$ represent energies of $(1+14 / 15) \times \mathrm{V}_{\mathrm{T}},(1+14 / 16) \times \mathrm{V}_{\mathrm{T}}$, and $(1+14 / 26) \times \mathrm{V}_{\mathrm{T}}$, where $\mathrm{V}_{\mathrm{T}}$ is the terminal voltage. These are the energies for nitrogen from the breakup of $\mathrm{NH}^{-}$, $\mathrm{NH}_{2}^{-}$, and $\mathrm{CN}^{-}$, respectively, but for molecular ions generated after the LE magnet, NOT in the ion source. The most intense peak by far is from $\mathrm{CN}^{-}$, a prolific and easily produced nitrogen ion (Anbar 1978). We also noted that when scanning the HE magnet with mass 14 injected, pA beams 


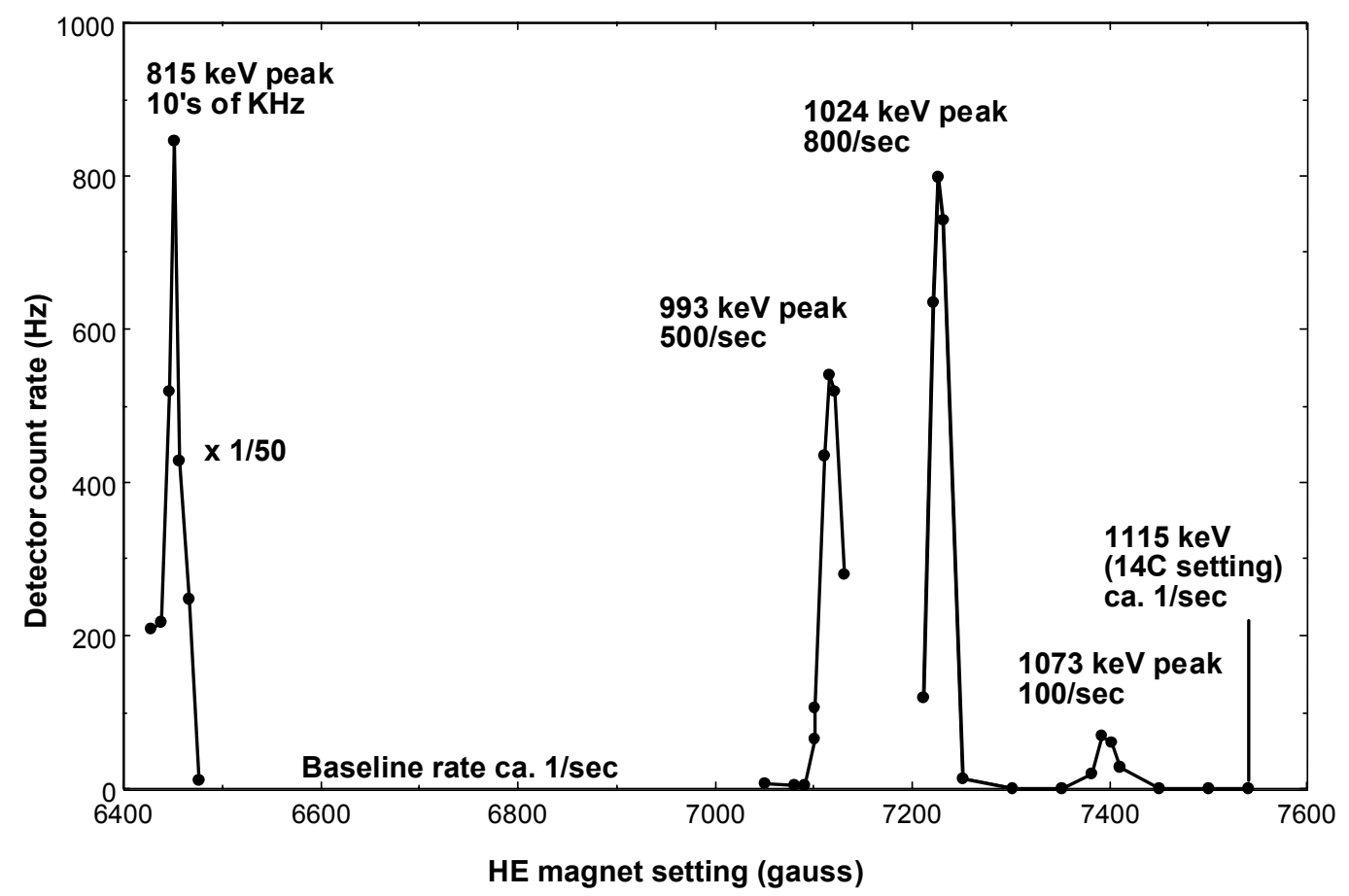

Figure 4 Detector count rate when the HE magnet and ESA are scanned together for mass 14 charge state $1+$ ions of different energies. The injection energy is $55 \mathrm{keV}$ and the accelerator terminal voltage is $530 \mathrm{kV}$, for a total ${ }^{14} \mathrm{C}$ energy of $1115 \mathrm{keV}$. Beam currents were reduced by a factor of $\sim 50$ to acquire data for the intense peak at the left of the plot. From left to right: the peaks are due to nitrogen from $\mathrm{CN}^{-}, \mathrm{NH}_{2}^{-}$, and $\mathrm{NH}^{-}$generated near the base of the accelerator, and to scattering from a ${ }^{13} \mathrm{C}$ beam injected as mass- $14 \mathrm{CH}^{-}$.

were observed at settings equivalent to ${ }^{16} \mathrm{O}$ at energies of 1060 and $1028 \mathrm{keV}$, corresponding to energies of $2 \times \mathrm{V}_{\mathrm{T}}$ and $(1+16 / 17) \times \mathrm{V}_{\mathrm{T}}$, or $\mathrm{O}^{+}$from $\mathrm{O}^{-}$and $\mathrm{OH}^{-}$ions, again generated at the base of the accelerator.

The basic background problem, then, is due to N-containing molecular ions generated between the LE magnet and the LE accelerator tube by some mechanism involving beams from the ion source. These low-energy $(\sim \mathrm{eV})$ ions drift into the LE accelerator tube, and some reach the stripper and break up. Some of the resulting $\mathrm{N}$ ions emerge from the stripper as $2+$ and charge exchange to $1+$ in the HE tube, acquiring sufficient extra energy to mimic ${ }^{14} \mathrm{C}$. The strong background enhancement at $\sim 4340$ gauss in Figure 2 must represent deflection of one of the intense beams from the source on to a region of the injector where production of the molecular ions is maximized.

Such backgrounds will typically not be a problem in larger ${ }^{14} \mathrm{C}$ AMS systems, where particle identification is used routinely; nor will they interfere in single-stage AMS systems (high-voltage decks) where only negative ions are accelerated. Small AMS systems accelerating $1^{+}$ions are vulnerable because they suffer from enhanced charge exchange in the HE accelerator tube due to high gas stripper pressures.

On discovering both $\mathrm{O}$ and $\mathrm{N}$ beams from the base of the accelerator, we leak-checked the area thoroughly but found nothing. Although the ultimate source of the nitrogen is probably air introduced during accelerator or ion source openings, the process is rather indirect, or use of nitrogen as the stripper gas would have had catastrophic results. It may require the buildup of nitrogen and other 
atoms in close proximity on interior surfaces of the vacuum system, where they can be sputtered as molecular ions by stray beams.

We realized that since most of the critical region between the LE magnet and the LE accelerator tube is part of the bouncer, running at a small positive bouncer potential when injecting ${ }^{14} \mathrm{C}$ should trap low-energy negative ions within the bouncer structure, thereby suppressing most of the background. This proved to be the case. Running the bouncer at +50 to $+100 \mathrm{v}$ rather than zero reduced the count rate from Alfa graphite by up to $80 \%$ and removed the off-mass background almost completely (Figure 2), and the stray oxygen beams also disappeared. A partial re-scan of the HE magnet/ESA combination showed that the $1024-\mathrm{keV}$ nitrogen peak in Figure 4 had been reduced by $90 \%$. Backgrounds equivalent to ages of $56 \mathrm{ka}$ (coal) and $54 \mathrm{ka}$ (calcite) were obtained from graphitized samples, together with an age of $62 \mathrm{ka}$ for Alfa graphite. Clearly, the background problem had been brought under control, if not eliminated completely.

We upgraded the injector vacuum system by adding a pumping restriction and a turbomolecular pump upstream of the LE magnet, in an attempt to reduce the background still further by reducing the periodic injections air and water from sample changer openings. However, this had little effect. Shortly, we will test the effect of adding a collimator and a negative bias ring immediately in front of the LE tube, mounted off the gap lens at the downstream end of the bouncer, to suppress the remaining $20 \mathrm{~cm}$ of beamline. Alternatively, since gas $\Delta \mathrm{E}-\mathrm{E}$ detectors with ultra-uniform silicon nitride entrance windows can resolve ${ }^{14} \mathrm{C}$ and ${ }^{14} \mathrm{~N}$ even at these low energies (M Suter, personal communication), the problem could be avoided by using particle identification, though at the expense of some increase in the cost and complexity of the system.

\section{Scattering}

We have also begun to investigate backgrounds due to scattering, especially from ${ }^{13} \mathrm{C}$. Figure 5 shows an oscilloscope trace of the detector amplifier output during the ${ }^{12} \mathrm{C},{ }^{13} \mathrm{C}$, and part of the ${ }^{14} \mathrm{C}$ bounce periods. It illustrates the very high count rates that occur when ${ }^{12} \mathrm{C}$ and ${ }^{13} \mathrm{C}$ beams are brought around the HE magnet. Some of these ions scatter from residual gas and pass through the magnet image slits, and still have energies sufficiently close to the nominal value to pass the ESA and reach the detector. Even after we added a tubular extension to an existing pumping restriction at the entrance to the HE magnet and improved the vacuum to an estimated $1 \times 10^{-7}$ torr at the $45^{\circ}$ point, we observed count rates of $\sim 5 \mathrm{KHz}$ per $\mu \mathrm{A}$ of analyzed ${ }^{12} \mathrm{C}$, and $50 \mathrm{KHz}$ per $\mu \mathrm{A}$ of ${ }^{13} \mathrm{C}$.

It is surprising that this mechanism can generate count rates when ${ }^{14} \mathrm{C}$ is being measured, since the only ${ }^{13} \mathrm{C}$ ions injected are mass- $14{ }^{13} \mathrm{CH}^{-}$or a high-energy ${ }^{13} \mathrm{C}^{-}$sputtering tail (Litherland 1984 ) at $14 / 13$ of the normal injection energy. The energy of ${ }^{13} \mathrm{C}^{+}$from $\mathrm{CH}^{-}$is $42 \mathrm{keV}$ too low at the HE magnet (gas scattering from this ${ }^{13} \mathrm{C}$ beam in the $\mathrm{HE}$ magnet produces the $1073-\mathrm{keV}$ peak in the $\mathrm{HE}$ magnet/ESA scan in Figure 4). Because of this energy mismatch, any gas-scattered ions should be rejected when the ESA is at normal ${ }^{14} \mathrm{C}$ settings. The intensity of the higher energy charge-exchange tail from this weak $(\sim 5 \mathrm{nA})$ beam is insufficient to provide a significant count rate via scattering. Measurements on analyzed beams after the HE magnet indicate that the sputter tail from our source ( $6.5 \mathrm{keV}$ sputtering energy) is below $1 \mathrm{pA}$ or $2 \times 10^{-6}$ of the primary beam when the system is tuned for an injection energy just $1.5 \mathrm{keV}$ higher than the actual source voltage setting of $55 \mathrm{kV}$. This suggests that the intensity of any beam tail injected at $14 / 13$ of the nominal energy is very small.

Nevertheless, it does appear that scattered ${ }^{13} \mathrm{C}$ background is significant. Experiments in collaboration with LLNL colleagues showed that enriched ${ }^{13} \mathrm{C}$ samples $\left(99 \%{ }^{13} \mathrm{C}\right)$ gave count rates on our system equivalent to ${ }^{14} \mathrm{C}$ samples of 5 to $10 \mathrm{pMC}$. The material was known to be ${ }^{14} \mathrm{C}$-dead from $4^{+}$ 


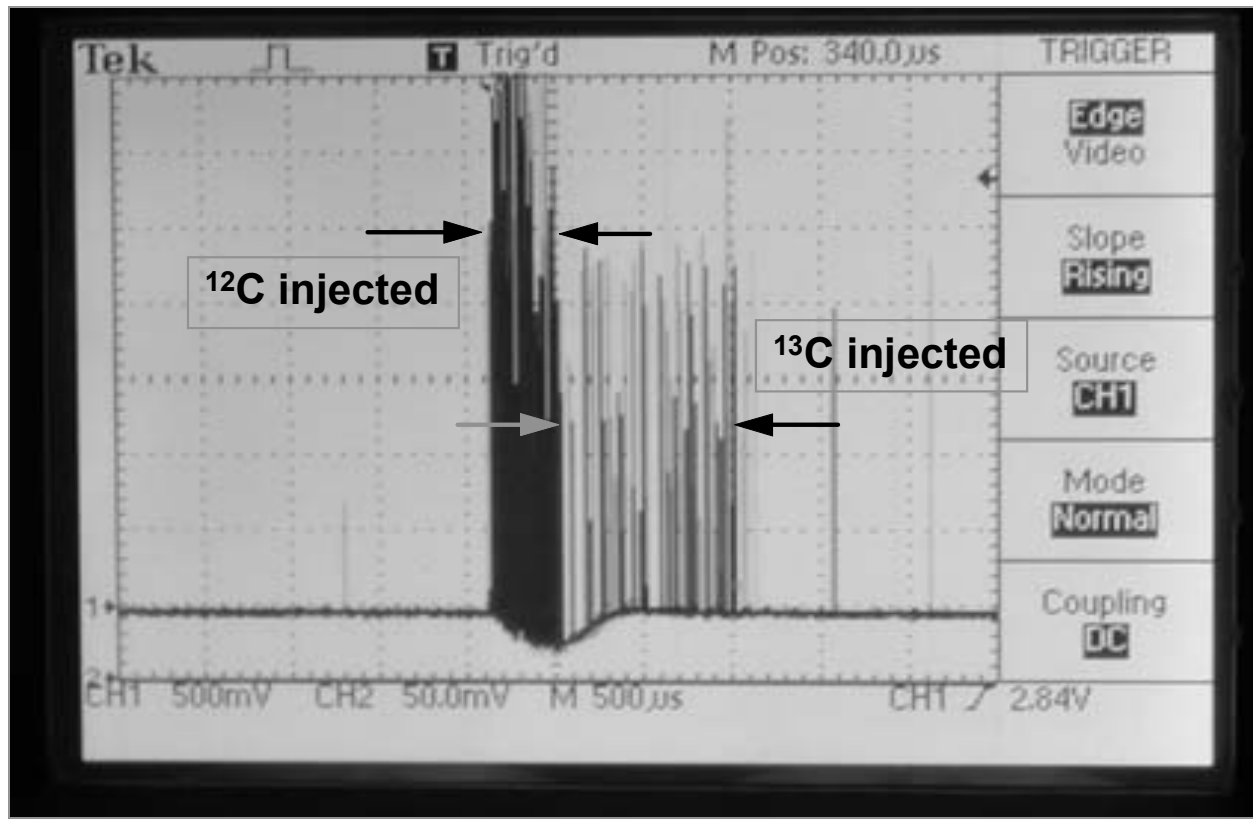

Figure 5 Detector amplifier output (oscilloscope trace). Very high scattering count rates are present when ${ }^{12} \mathrm{C}$ and ${ }^{13} \mathrm{C}$ are brought around the $\mathrm{HE}$ magnet—so high that pulse pileup and amplifier baseline shifts occur — though the system recovers well before ${ }^{14} \mathrm{C}$ counting begins.

AMS measurements at $6.5 \mathrm{MV}$. Count rates equivalent to $30 \mathrm{pMC}$ (T Ognibene, personal communication) were observed on a small NEC AMS system at LLNL (Ognibene et al. 2000), similar to ours but with poorer vacuum in the HE magnet. Scaling the results for our system to samples of normal ${ }^{13} \mathrm{C}$ content, we can expect backgrounds in the $0.05-0.1 \mathrm{pMC}$ range.

Resolving this residual ${ }^{13} \mathrm{C}$ background from ${ }^{14} \mathrm{C}$ via particle identification appears problematic at these low energies (M Suter, personal communication). In principle, the problem could be solved by adding a third dispersive element, i.e., replacing the ESA with a second $90^{\circ}$ magnet, followed by a Wien Filter acting in the vertical. Two-magnet systems have been used since the early days of AMS, specifically to remove any scattered beam component. However, these changes would add significantly to the cost and size of the small system. Alternatively, vacuum in the HE magnet could be improved by moving it further from the accelerator to accommodate an additional pumping restriction and a second pumping stage, but this would require changes to the entire HE beamline geometry, and might result in beam losses in the magnet.

\section{CONCLUSIONS}

The Keck Carbon Cycle AMS lab is now operating routinely. In the process of setting up the system, we have identified a previously unreported ${ }^{14} \mathrm{C}$ AMS background: charge exchange tails from ${ }^{14} \mathrm{~N}$ beams derived from nitrogen-containing molecular ions produced near the entrance of the accelerator. We have suppressed most of this background by appropriately biasing internal electrodes and the problem could also be solved by using E- $\Delta$ E particle identification. Scattering of ${ }^{13} \mathrm{C}$ in the $\mathrm{HE}$ magnet generates additional backgrounds in systems such as ours that lack a third (anti-scatter) dispersive element. Nevertheless, we have achieved blank levels in this new facility that are comparable with those of larger AMS systems, at a fraction of the cost. 


\section{ACKNOWLEDGEMENTS}

We thank Jim Schroeder, Thilo Hauser, Bob Templin, Roger Loger, Mark Sundquist, and others at NEC for their assistance, Ted Ognibene and Darren Hillegonds of LLNL for help with background tests, and the W M Keck Foundation, the Vice Chancellor for Research, and the Dean of Physical Sciences, UC Irvine, for financial support.

\section{REFERENCES}

Anbar M. 1978. The limitations of mass spectrometric radiocarbon dating using $\mathrm{CN}^{-}$ions.

Goslar T, Czernik J, Goslar E. Forthcoming. Low-energy ${ }^{14} \mathrm{C}$ AMS in Poznan Radiocarbon Laboratory, Poland. Proceedings of the 9th International Conference on AMS. Nuclear Instruments and Methods in Physics Research $B$.

Gove HE, editor. Proceedings of the 1st Conference on Radiocarbon Dating with Accelerators. Rochester: University of Rochester. p 152-5.

Jacob SAW, Suter M, and Synal H-A. 2000. Ion beam interaction with stripper gas-key for AMS at sub MeV. Nuclear Instruments and Methods in Physics Research B 172:235-41.

Litherland AE. 1984. Accelerator mass spectrometry. Nuclear Instruments and Methods in Physics Research B 5:100-8.

Ognibene TJ, Brown TA, Knezovich JP, Roberts ML, Southon JR, Vogel JS. 2000. Ion-optics calculations of the LLNL AMS system for biochemical ${ }^{14} \mathrm{C}$ measurements. Nuclear Instruments and Methods in Physics Research B 172:47-51.

Roberts ML, Culp RA, Dvoracek DK, Hodgins GWL, Neary MP, Noakes JE. Forthcoming. The compact ${ }^{14} \mathrm{C}$ AMS system at the University of Georgia. Proceedings of the 9th International Conference on AMS. $\mathrm{Nu}$ clear Instruments and Methods in Physics Research B.

Southon JR, Santos GM. 2004. Ion Source Development at KCCAMS, University of California, Irvine. Radiocarbon, these proceedings.

Synal H-A, Jacob S, Suter S. 2000. The PSI/ETH small radiocarbon dating system. Nuclear Instruments and Methods in Physics Research B 172:1-7. 